\title{
Capacitor Placement and Reconfiguration of Distribution System with hybrid Fuzzy-Opposition based Differential Evolution Algorithm
}

\author{
R.MuthuKumar ${ }^{1}$, Dr.K.Thanushkodi ${ }^{2}$ \\ ${ }^{1}$ (Research Scholar, Anna University, Tamilnadu, India) \\ ${ }_{2}^{2}$ (Director, Akshaya College of Engineering and Technology, Coimbatore, Tamilnadu, India)
}

\begin{abstract}
Distribution system reconfiguration and optimal capacitor placement are the two techniques adapted for the control of power loss. These techniques not only control the power loss but also control volt/var of the distribution system, and improve the system reliability and security. This paper proposes a method to handle reconfiguration and capacitor placement simultaneously for the effective optimization. In order to consider the constraints along with the objective, heuristic fuzzy has been integrated with ODE. The effectiveness of the proposed approach is demonstrated by employing the feeder switching operation scheme to IEEE-33 bus Power Distribution systems. The proposed algorithm reduces the transmission loss and controls volt/var while satisfying power flow constraints.
\end{abstract}

Keywords -Capacitor placement, Differential evolution, Distribution network reconfiguration, Loss reduction, Switching operation

\section{Introduction}

Development of electrical power distribution system performance requires proper plans for increasing utilities efficiency, for instance, losses reduction. Different approaches are used to reduce losses such as optimal use of electrical equipments, optimal use of loading at the transformers, reconfiguration, and optimal capacitor placement, optimal placement of DG (Distributed Generation) and removal of harmonics. Amongst all, reconfiguration and capacitor placement are comparatively lesser operating cost. The reconfiguration of a distribution system is a process, which alters the feeder topological structure by changing the open/close status of the switches in the distribution system. The presence of high number of switching elements in a radial distribution system makes the network reconfiguration a highly complex combinatorial, non-differentiable and constrained non-linear mixed integer optimization problem. Also, the number of variables varies with respect to the size of the system. The distribution system with 'n' switches will have 'n' variables. The demand for a radial operation also makes the mathematical model more difficult to represent efficiently and codification of a solution becomes difficult when metaheuristic techniques are employed. Even though reconfiguration strategy has above said limitations, it is a most widely recommended and most successful strategy with zero operating cost.

The feeder reconfiguration problem has been dealt in various papers. Civanlar et al.[1] conducted the early work on feeder reconfiguration for loss reduction. In [2], Baran et al. defined the problem of loss reduction and load balancing as an integer programming problem. Aoki et al. [3] developed a method for load transfer, in which the load indices were used for load balancing. In Shirmohammadi and Hong [4], the solution method starts with a meshed distribution system obtained by considering all switches closed. Then, the switches are opened successively to eliminate the loops. Developments in algorithm design techniques such as simulated annealing [5], heuristic fuzzy [6], Artificial Neural Network [7], population based evolutionary algorithms [8-9] provides much improvement in reconfiguration strategy. The plant growth simulation algorithm (PGSA) is employed to optimize the network configuration of the distribution system [10]. The PGSA provides a detailed description on switch state and decision variables, which greatly contracts the search space and hence reduces computation effort. In [11], harmony search algorithm has been proposed for reconfiguration.

As the nature of capacitor placement problem is complex combinatorial, different techniques have been followed by the authors in the past. The initial contribution was made by Schmill [12] using 2/3 rule for capacitor placement. Dynamic programming with assuming the capacitor sizes as discrete variables adapted by Duran [13]. The capacitor problem was viewed as a nonlinear problem by Grainger et al. [14], where variables were treated as continuous. The improvements in advanced optimization techniques such as genetic algorithm, micro genetic, particle swarm optimization, ant colony and differential evolution allowed the optimization procedures comparatively easier than the conventional procedures. Optimal capacitor placement was carried out through genetic algorithm by [15]. The number of locations was considered as the total variables for genetic algorithm. The microgenetic concepts involving enhanced genetic algorithm was proposed in [16]. The power 
flow constraints were handled through fuzzy logic concepts. Optimization procedure through particle swarm optimization principle was adapted in [17]. Optimization through plant growth simulation algorithm (PGSA) was first introduced for feeder reconfiguration in [12]. Later, the PGSA along with loss sensitivity factors was introduced [18] for optimal capacitor placement. Loss sensitivity factors were used to find the optimal location i.e weak buses which require capacitor. PGSA was incorporated in order to find out the optimal sizing of the capacitors.

The optimization procedure combining both capacitor placement and reconfiguration was recently introduced. In [19], the ant colony optimization algorithm was introduced for the optimization. The combined usage of deterministic approach and heuristic technique for network reconfiguration and optimal capacitor placement for power-loss reduction and voltage profile improvement in distribution networks [20]. The improved reconfiguration method along with GA used for simultaneous reconfiguration and capacitor placement for distribution network optimization in [21].

In this paper, Opposition based Differential Evolution [22] algorithm has been presented for simultaneous handling of reconfiguration and optimal capacitor placement. Further, heuristic fuzzy has been incorporated to look at constraints with objective. The effectiveness of the proposed approach is demonstrated by employing the feeder switching operation scheme to IEEE-33 bus.

\section{Problem Formulation}

The main objective of the optimal capacitor placement is to minimize the total annual cost of the system subject to the power flow constraints such as bus voltage $\left(\left|\mathrm{V}_{\min }\right|<\left|\mathrm{V}_{\mathrm{i}}\right|<\mid \mathrm{V}_{\max }\right)$, branch currents $\quad\left(\left|\mathrm{I}_{\mathrm{j}}\right|<\right.$ $\left.\left|I_{\max , j \varepsilon n}\right|\right)$ and radiality constraints. The mathematical equation relevant to the objective function of the problem is defined as,

$\mathrm{F}=\operatorname{Minimize}(\mathrm{C})$

Where, the term ' $\mathrm{C}$ ' represents the total cost of the distribution system, it includes the cost for energy loss and capacitor cost.

The problem carried out with following assumptions.

(i) Loads are static

(ii) Distribution system is perfectly balanced

(iii) Well reactive power compensated system

(iv) Operation and maintenance costs of the capacitors are negligible.

The single line diagram of the balanced distribution system shown in the Figure 1 used to describe the load flow calculations. In Figure $1, \mathrm{P}_{\mathrm{i}}$ and $\mathrm{Q}_{\mathrm{i}}$ represents the real and reactive power flow between the sending and receiving end buses, $\mathrm{P}_{\mathrm{Li}}$ and $\mathrm{Q}_{\mathrm{Li}}$ denotes the real and reactive power loads. The line resistance and reactance are denoted as $\mathrm{R}_{\mathrm{i}, \mathrm{j}}$ and $\mathrm{X}_{\mathrm{i}, \mathrm{j}} \cdot \frac{y_{i}}{2}$ is the total shunt admittance at bus $\mathrm{i}$

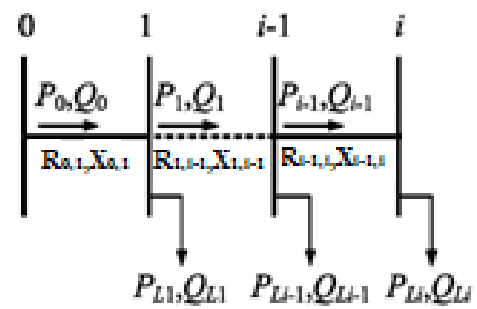

Figure 1 Single line diagram of a main feeder

The following set of equations are used to calculate the power flow,

$$
\begin{aligned}
& \mathrm{P}_{\mathrm{i}+1}=\mathrm{P}_{\mathrm{i}}-\mathrm{P}_{\mathrm{Li}+1}-\mathrm{R}_{\mathrm{i}, \mathrm{i}+1} \frac{\mathrm{P}_{\mathrm{i}}^{2}+\mathrm{Q}_{\mathrm{i}}^{2}}{\mathrm{~V}_{\mathrm{i}}^{2}} \\
& \mathrm{Q}_{\mathrm{i}+1}=\mathrm{Q}_{\mathrm{i}}-\mathrm{Q}_{\mathrm{Li}+1}-\mathrm{X}_{\mathrm{i}, \mathrm{i}+1} \frac{\mathrm{P}_{\mathrm{i}}^{2}+\mathrm{Q}_{\mathrm{i}}^{2}}{\mathrm{~V}_{\mathrm{i}}^{2}}-\mathrm{V}_{\mathrm{i}}^{2} \frac{y_{i}}{2} \\
& \mathrm{~V}_{\mathrm{i}+1}^{2}=\mathrm{V}_{\mathrm{i}}^{2}-2\left(\mathrm{R}_{\mathrm{i},+1} \mathrm{P}_{\mathrm{i}}+\mathrm{X}_{\mathrm{i}, \mathrm{i}+1} \mathrm{Q}_{\mathrm{i}}\right)+\left(\mathrm{R}_{\mathrm{i},+1}^{2}+\mathrm{X}_{\mathrm{i},+1}^{2}\right) \frac{\mathrm{P}_{\mathrm{i}}^{2}+\mathrm{Q}_{\mathrm{i}}^{2}}{\mathrm{~V}_{\mathrm{i}}^{2}}
\end{aligned}
$$


The power loss $\mathrm{P}_{\mathrm{F}, \mathrm{L} \text { oss }}$ of the feeder is determined by summing the losses of all line sections of the feeder and it is given by,

$$
\mathrm{P}_{\mathrm{F}, \text { Loss }}=\sum_{\mathrm{i}=1}^{\mathrm{nl}} \mathrm{R}_{\mathrm{i}, \mathrm{i}+1} \frac{\mathrm{P}_{\mathrm{i}}^{2}+\mathrm{Q}_{\mathrm{i}}^{2}}{\mathrm{~V}_{\mathrm{i}}^{2}}
$$

The total energy loss cost $\left(\mathrm{E}_{\text {cost }}\right)$ has been calculated as,

$$
\mathrm{E}_{\text {cost }}=\mathrm{P}_{\mathrm{T}, \text { loss }} * \mathrm{~K}_{\mathrm{p}} \text {; }
$$

where $\mathrm{K}_{\mathrm{p}}$ is the equivalent annual cost of power loss in $\$ /(\mathrm{kW}$-year)

In general, the cost per KVAR varies with respect to their size. The available capacitor sizes and their cost (K) were given in [19]. The total cost of the distribution system is given in equation (7).

$$
\mathrm{C}=\mathrm{E}_{\text {cost }}+\mathrm{C}_{\mathrm{q}, \mathrm{cost}}
$$

where,

$$
\begin{aligned}
& \mathrm{C}_{\mathrm{q}, \text { cost }}=\mathrm{C}_{\mathrm{q}, \mathrm{fixed}}+\mathrm{C}_{\mathrm{i}}^{\text {annual }} * \mathrm{Q}_{\mathrm{i}} \\
& \mathrm{C}_{\mathrm{q}, \mathrm{fixed}} \text { is the fixed cost for the capacitor placement } \\
& \quad \$ / \text { year } \\
& \mathrm{C}_{\mathrm{i}}^{\text {annual }} \text { is the annual cost for the capacitor installation } \\
& \quad \text { in } \$ /(\mathrm{KVAR} \text {-year) } \\
& \quad \text { (i is the selected buses for capacitor installation) } \\
& \mathrm{Q}_{\mathrm{i}} \quad \text { is the reactive power in (KVAR) }
\end{aligned}
$$

\section{Search Strategy For Capacitor Sizing Through Ode Algorithm}

Opposition based differential algorithm is a recent evolutionary algorithm with enhanced features such as self acceleration, self migration and assured optimal search with least population size. The efficiency of the algorithm can be well proven by applying into complex and/or large problems. In this paper, the purpose of introduction of ODE is to find the optimal location for capacitor placement, optimal capacitor size and optimal configuration. The number of variables for ODE searching is the total of number of loops, number of locations and number of locations (for proper sizing). For instance, the system with ' $\mathrm{x}$ ' loops and ' $y$ ' locations will require ' $\mathrm{x}+2 \mathrm{y}$ ' ODE variables.

\section{Fuzzy Operations For Multi-Objective Capacitor Placement}

In fuzzy domain, each objective is associated with a membership function. The membership function indicates the degree of satisfaction of the objective. In the crisp domain, either the objective is satisfied or it is violated, implying membership values of unity and zero, respectively. When there are multiple objectives to be satisfied simultaneously, a compromise has to be made to get the best solution. The four objectives such as power loss minimization, total cost minimization, bus voltage deviation minimization and branch current deviation minimization are fuzzified and dealt by integrating them into a min-max imperative of fuzzy satisfaction objective function.

In the proposed method for system optimization, the terms $\mu_{\mathrm{Fj}}, \mu_{\mathrm{Cj}}, \mu_{\mathrm{Vj}}$ and $\mu_{\mathrm{Ij}}$ indicate the membership function for power loss reduction, total cost reduction, bus voltage deviation and branch current deviation respectively of the $\mathrm{j}^{\text {th }}$ configuration. The higher membership value implies a greater satisfaction with the solution. The membership function consists of a lower and upper bound value together with a strictly monotonically decreasing and continuous function.

\subsection{Fuzzy-set Model for Power Loss Minimization}

The deviation of power loss of the new configuration $\left(\mathrm{P}_{\text {nloss }}\right)$ to the previous configuration loss $\left(\mathrm{P}_{\text {oloss }}\right)$ is to be identified with the objective of minimizing the system power loss. The power loss of the system has been obtained from radial load flow for each new configuration. Moreover, the amount of the $\mathrm{P}_{\text {nloss }}$ resulting from capacitor inclusion can be estimated as 'very close, 'close' or 'not close' to the $\mathrm{P}_{\text {oloss. }}$ Therefore, the linguistic terms can be formulated as a membership function by the fuzzy notation. The membership function $\mu_{\mathrm{Fj}}$ has been depicted using Equation (8). A small difference between $\mathrm{P}_{\text {nloss }}$ and $\mathrm{P}_{\text {oloss }}$ possesses a larger membership value. The membership function at $\mathrm{j}^{\text {th }}$ configuration can be expressed as follows, 


$$
\mu_{\mathrm{Fj}}= \begin{cases}\frac{\mathrm{X}_{\max }-\mathrm{X}_{\mathrm{j}}}{\mathrm{X}_{\max }-\mathrm{X}_{\text {min }}} & \text { for } \mathrm{X}_{\text {min }}<\mathrm{X}_{\mathrm{j}}<\mathrm{X}_{\max } \\ 1.0 & \text { for } \mathrm{X}_{\mathrm{j}} \leq \mathrm{X}_{\text {max }} \\ 0.0 & \text { for } \mathrm{X}_{\mathrm{j}} \geq \mathrm{X}_{\text {max }}\end{cases}
$$

where, $X_{j}=P_{\text {nloss }} / P_{\text {tloss }}$

\section{Simulation Results}

The effectiveness of the algorithm has been validated through IEEE 33-bus test distribution system [19]. The system has 5 normally opened switches, 32 normally closed switches with 33 buses and it is assumed as balanced three-phase with $12.66 \mathrm{kV}$. The corresponding power loss is $202.7 \mathrm{~kW}$. It has been carried out by considering the system working under normal conditions, i.e., all the branches are being loaded without violating its limits, voltage at the buses is within limit and the phases are balanced.

The optimization process starts with identifying the total variables, such as number of locations for capacitor placement and loops present in the distribution system. For the test system, it has been considered as 5 loops and 3 locations for the capacitor placement based on experience and earlier studies. Therefore, total number of variables required for ODE searching is 11(ie. 5 for loops, 3 for locations and 3 for sizing).

\subsection{Variable Size}

For the 5 loops, as per the PGSA [10], decision variables are designed for the system, which is shown in Fig. 2.

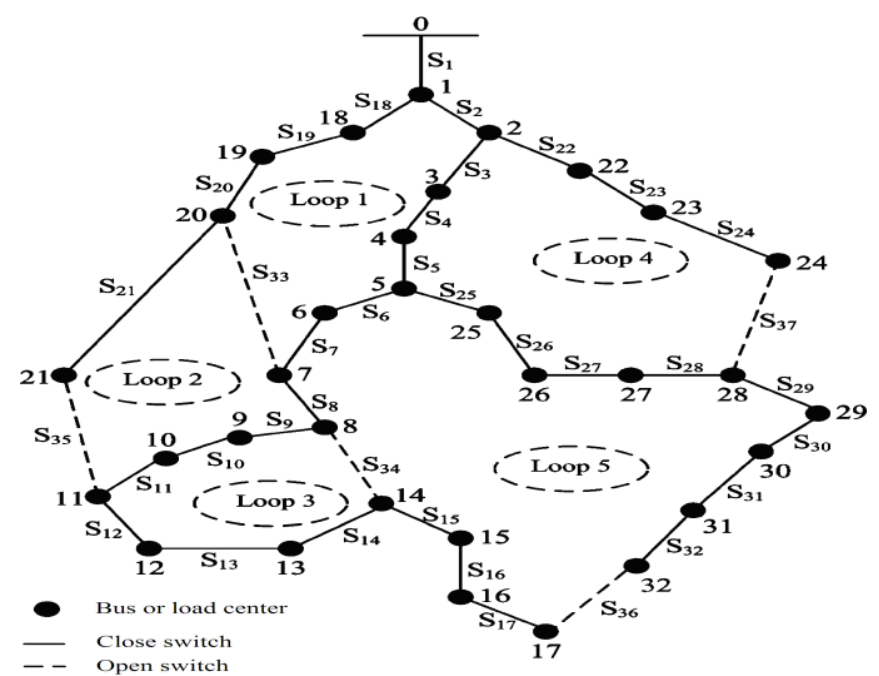

Figure 2 IEEE 33-bus RDS with state variable sketch

The description of the switch states is identified as,

i. the open switches are $S_{33}, S_{34}, S_{35}, S_{36}$, and $S_{37}$;

ii. the closed switches are $S_{1}$ to $S_{32}$;

iii. the permanently closed switches are $S_{1}, S_{2}, S_{3}, S_{18}$ and $S_{22}$ (since these switches are near to the feeder);

iv. the temporary closed state switches are $S_{3}, S_{4}, S_{5}, S_{6}, S_{7}, S_{8}, S_{9}, S_{10}, S_{11}, S_{25}, S_{26}, S_{27}$, and $S_{28}$ (since these switches are common to more than one loop;

As a result, the solution sets are re-defined as,

$$
\begin{aligned}
& \mathrm{L}_{1}=\left\{\mathrm{S}_{4}, \mathrm{~S}_{5}, \mathrm{~S}_{6}, \mathrm{~S}_{7}, \mathrm{~S}_{20}, \mathrm{~S}_{19}, \mathrm{~S}_{33}\right\} \\
& \mathrm{L}_{2}=\left\{\mathrm{S}_{8}, \mathrm{~S}_{9}, \mathrm{~S}_{10}, \mathrm{~S}_{11}, \mathrm{~S}_{21}, \mathrm{~S}_{35}\right\} \\
& \mathrm{L}_{3}=\left\{\mathrm{S}_{12}, \mathrm{~S}_{13}, \mathrm{~S}_{14}, \mathrm{~S}_{34}\right\} \\
& \mathrm{L}_{4}=\left\{\mathrm{S}_{25}, \mathrm{~S}_{26}, \mathrm{~S}_{27}, \mathrm{~S}_{28}, \mathrm{~S}_{23}, \mathrm{~S}_{24}, \mathrm{~S}_{37}\right\} \\
& \mathrm{L}_{5}=\left\{\mathrm{S}_{15}, \mathrm{~S}_{16}, \mathrm{~S}_{17}, \mathrm{~S}_{32}, \mathrm{~S}_{31}, \mathrm{~S}_{30}, \mathrm{~S}_{29}, \mathrm{~S}_{36}\right\}
\end{aligned}
$$


The equation (9) reveals that the system has five loops with set of switches. The searching for the best set of open switches from each loop has been carried out with ODE. The number of switches present in each loop such as 7,6,4,7 and 8 defines the range for the variables. Therefore, the range for the searching process is selected as (1-7), (1-6), (1-4), (1-7) and (1-8) for the variables $\mathrm{L}_{1}, \mathrm{~L}_{2}, \mathrm{~L}_{3}, \mathrm{~L}_{4}$ and $\mathrm{L}_{5}$ respectively.

For location variables, total number of buses except feeder bus has been considered as the maximum range for the variables. For ' $n$ ' bus system, the maximum value of the variable has to be ' $n-1$ '.

For capacitor sizing variables, the range for the variables and corresponding cost has been shown in Table $1[18]$.

Table 1 Capacitor sizes and cost

\begin{tabular}{|c|c|c|c|c|c|}
\hline $\begin{array}{c}\text { Sl. } \\
\text { No. }\end{array}$ & $\begin{array}{c}\text { Q in } \\
\text { kVAR }\end{array}$ & $\begin{array}{c}\text { Capacitor cost } \\
\text { in } \mathbf{\$ / k V A R}\end{array}$ & $\begin{array}{c}\text { Sl. } \\
\text { No. }\end{array}$ & $\begin{array}{c}\text { Q in } \\
\mathbf{k V A R}\end{array}$ & $\begin{array}{c}\text { Capacitor cost } \\
\text { in } \mathbf{\$} / \mathbf{k} \text { AR }\end{array}$ \\
\hline 1 & 150 & 0.500 & 15 & 2250 & 0.197 \\
\hline 2 & 300 & 0.350 & 16 & 2400 & 0.170 \\
\hline 3 & 450 & 0.253 & 17 & 2550 & 0.189 \\
\hline 4 & 600 & 0.220 & 18 & 2700 & 0.187 \\
\hline 5 & 750 & 0.276 & 19 & 2850 & 0.183 \\
\hline 6 & 900 & 0.183 & 20 & 3000 & 0.180 \\
\hline 7 & 1050 & 0.228 & 21 & 3150 & 0.195 \\
\hline 8 & 1200 & 0.170 & 22 & 3300 & 0.174 \\
\hline 9 & 1350 & 0.207 & 23 & 3450 & 0.188 \\
\hline 10 & 1500 & 0.201 & 24 & 3600 & 0.170 \\
\hline 11 & 1650 & 0.193 & 25 & 3750 & 0.183 \\
\hline 12 & 1800 & 0.187 & 26 & 3900 & 0.182 \\
\hline 13 & 1950 & 0.211 & 27 & 4050 & 0.179 \\
\hline 14 & 2100 & 0.176 & & & \\
\hline
\end{tabular}

\subsection{Implementation}

For instance for variable $\mathrm{L}_{1}$, by the control strategy "DE/current-to-rand/1" the value generated is 3 then $S_{6}$ is the switch assumed as opened in the loop 1 and the same process is continued for the rest of the variables. The initial population and their respective losses were calculated and stored. With the initial values of $\mathrm{F}=0.8$ and $\mathrm{CR}=0.6$ searching was done for the fixed number of iterations. The proposed method reduces the power loss from $202.67 \mathrm{~kW}$ to $101.42 \mathrm{~kW}$, and maintains the bus voltages well above minimum value. The kVAR at the buses 27,28 and 29 are 149,727 and 149 respectively. With the effective influence of capacitors at the optimal locations the total operating cost of the system has been reduced from 34,049.75 \$/Year to $18,198.96 \$ /$ Year. Thus the proposed algorithm has achieved $46.55 \%$ of cost saving with the combined reconfiguration-optimal capacitor placement case. Furthermore, the bus voltages are maintained within the limit. The results of the three cases are compared in Table 2 along with the results of the previous published work [20]. From the Table, it is understood that the annual operating cost and power loss has been greatly reduced with the combined reconfiguration and capacitor placement approach.

Table 2 Summary of results for 33-bus RDS

\begin{tabular}{|c|c|c|c|c|c|}
\hline Parameters & $\begin{array}{c}\text { Initial } \\
\text { Configuration }\end{array}$ & $\begin{array}{c}\text { Reconfiguration } \\
\text { Only } \\
{[10]}\end{array}$ & $\begin{array}{c}\text { Capacitor } \\
\text { Placement } \\
\text { Only } \\
{[18]}\end{array}$ & $\begin{array}{c}\text { Reconfiguration } \\
\text { and Capacitor } \\
\text { Placement } \\
{[20]}\end{array}$ & $\begin{array}{c}\text { Proposed } \\
\text { Reconfiguration } \\
\text { and Capacitor } \\
\text { Placement }\end{array}$ \\
\hline Loss $(\mathrm{kW})$ & 202.67 & 139.54 & 159.89 & 101.49 & 101.42 \\
\hline $\begin{array}{c}\text { Min. bus } \\
\text { Voltage (pu) }\end{array}$ & 0.913 & 0.9378 & 0.933 & 0.957 & 0.959 \\
\hline $\begin{array}{c}\text { Total } \\
\text { Capacitor } \\
\text { size (kVAR) } \\
\end{array}$ & - & - & 2940 & 1685 & 1027 \\
\hline $\begin{array}{c}\text { Power Loss } \\
\text { Cost } \\
(\$ /(K W-y r))\end{array}$ & - & 23444.62 & 26861.59 & 17038.56 & 17039.03 \\
\hline $\begin{array}{l}\text { Capacitor } \\
\text { Cost }(\$ / y r)\end{array}$ & - & - & 1529.87 & 722.84 & 159.94 \\
\hline $\begin{array}{c}\text { Total Annual } \\
\text { Cost }(\$ / y r)\end{array}$ & 34049.75 & 23444.62 & $28,391.46$ & 18761.4 & 18198.96 \\
\hline $\begin{array}{c}\% \\
\text { saving } \\
\end{array}$ & - & 31.14 & 16.61 & 44.9 & 46.55 \\
\hline
\end{tabular}

\section{Conclusion}

An efficient approach that combines the reconfiguration and optimal capacitor placement for power loss reduction and bus voltage improvement has been proposed in this paper. ODE has taken care of 
reconfiguration, optimal capacitor location and capacitor sizing. With the effective inclusion of heuristic fuzzy, the power flow constraints were considered along with loss reduction. The proper use of ODE improves the efficiency in terms of reduced number of load flow executions, reduced computational executions and removal of unfeasible solutions in the search space. The results obtained with the present approach, when compared with the previous methods proposed by the authors shows that the introduction of the algorithm with hybrid FODE has contributed to reduce the number of power flows and has incorporated the network constraints. Hence with the effective introduction of the proposed algorithm, loss reduction was done subjected under constraints such as bus voltage limit and branch current limit and can be applied to any large real radial distribution system supplied from both single and multi feeders.

\section{References}

[1] S. Civanlar, J. J. Grainger, H. Yin, and S. S. H. Lee, "Distribution feeder reconfiguration for loss reduction," IEEE Trans. Power Del., vol. 3, no. 3, pp. 1217-1223, Jul. 1988.

[2] Baran ME and Wu FF, "Network reconfiguration in distribution systems for loss reduction and load balancing," IEEE Trans. Power Del., vol. 4, no. 1, pp. 401-1407, Jan. 1989.

[3] Aoki K, Kawabara H, and Satoh. M, "An efficient algorithm for load balancing of transformers and feeders," IEEE Trans. Power Del., vol. 3, no. 4, pp. 1865-1872, Jul. 1988

[4] D. Shirmohammadi and H.W. Hong, "Reconfiguration of electric distribution networks for resistive line losses reduction," IEEE Trans. Power Del., vol. 4, no. 2, pp. 1492-1498, Apr. 1989.

[5] H. C. Cheng and C. C. Ko, "Network reconfiguration in distribution systems using simulated anealing", Elect. Power Syst. Res., vol. 29, pp. 227-238, May 1994.

[6] K. Huang and H. Chin, "Distribution feeder energy conservation by using heuristics fuzzy approach," Electrical Power and Energy Systems, vol. 24,pp. 439-445, 2002.

[7] H. Salazar, R. Gallego, and R. Romero, "Artificial neural networks and clustering techniques applied in the reconfiguration of distribution sys- tems," IEEE Trans. Power Del., vol. 21, no. 3, pp. 1735-1742, 2006.

[8] Ying-Yi .H and Saw-Yu .H, "Determination of network configuration considering multiobjective in distribution systems using genetic algorithms", IEEE Trans. on Power Sys., vol. 20, no. 2, pp. 1062-1069, 2006.

[9] K. Qin and P. N. Suganthan, "Self-adaptive differential evolution algorithm for numerical optimization," in Proc. IEEE Congr. Evolut. Comput., Edinburgh, Scotland, , pp. 1785-1791, 2005

[10] Wang and H.Z. Cheng, "Optimization of Network configuration in Large distribution systems using plant growth simulation algorithm,” IEEE Trans. Power Syst., vol.23, No. 1, pp. 119-126, 2008.

[11] R. Srinivasa Rao, S. V. L. Narasimham, M. Ramalinga Raju, and A. Srinivasa Rao, "Optimal network reconfiguration of large-scale distribution system using harmony search algorithm," IEEE Trans. on Power Systems, vol. 26, no. 3, pp. 1080-1088, 2011.

[12] Schmill JV. Optimum size and location of shunt capacitors on distribution feeders. IEEE Trans Power Apparat Syst; 84:825-32, 1965.

[13] Duran H. Optimum number, location and size of shunt capacitors in radial distribution feeders: a dynamic programming approach. IEEE Trans Power Apparat Syst.., 87:1769-74, 1968.

[14] Grainger JJ, Lee SH, " Optimum size and location of shunt capacitors for reduction of losses on distribution feeders", IEEE Trans Power Apparat Syst;100(3):1105-18, 1981.

[15] Das D, “ Reactive power compensation for radial distribution networks using genetic algorithms", Electrical Power Energy Syst.,24:573-81, 2002.

[16] B. A. Souza, H. N. Alves, and H. A. Ferreira, "Microgenetic algorithms and fuzzy logic applied to the optimal placement of capacitor banks in distribution networks," IEEE Trans. Power Syst., vol. 19, no. 2, pp. 942-947, May 2004.

[17] Prakash K, Sydulu M, "Particle swarm optimization based capacitor placement on radial distribution systems" IEEE power engineering society, general meeting; 2007. p. 1-5.

[18] Srinivasas Rao R, Narasimham S.V.L, Ramalingaraju M, "Optimal capacitor placement in a radial distribution system using Plant Growth Simulation Algorithm”, Electrical Power Energy Syst 2011;33: 1133-1139.

[19] M. J. Kasaei and M. Gandomkar, "Loss Reduction in Distribution Network Using Simultaneous Capacitor Placement and Reconfiguration With Ant Colony Algorithm”, IEEE Proceeding, DOI: 978-1-4244-4813-5/10, 2010.

[20] Diana P. Montoya and Juan M, "Reconfiguration and optimal capacitor placement for losses reduction", IEEE Proceedings, DOI: 978-1-4673-2673-5, 2012.

[21] Farahai, Behrooz and Hossein, "Reconfiguration and capacitor placement simultaneously for energy loss reduction based on an improved reconfiguration method," IEEE Trans. Power Syst., vol. 27, no. 2, pp. 587-595, May 2012.

[22] S. Rahnamayan, R. Tizhoosh, and M. A. Salama, "Opposition-Based Differential Evolution," IEEE Trans. on Evolutionary Computation, vol. 12, no. 1, pp. 64-79, 2008. 